This article is licensed under the Creative Commons Attribution-NonCommercial 4.0 International License (CC BY-NC) (http://www.karger.com/Services/OpenAccessLicense). Usage and distribution for commercial purposes requires written permission.

\title{
Pentalogy of Fallot Firstly Diagnosed before Emergency Vertebral Surgery in an Adult Patient
}

\author{
Xiaofeng Lu ${ }^{a} \quad$ Yinglu Zhao ${ }^{a} \quad$ Wenzhu Dang ${ }^{b}$ Yuanjun Teng \\ Debin Liu ${ }^{\mathrm{a}}$ \\ aDepartment of Cardiac Surgery, Lanzhou University Second Hospital, Lanzhou, PR China; \\ bDepartment of Ultrasound Diagnostic, Lanzhou University Second Hospital, Lanzhou, PR \\ China; 'Department of Orthopedics, Lanzhou University Second Hospital, Lanzhou, PR \\ China
}

\section{Keywords}

Pentalogy of Fallot · Emergency vertebral surgery · Adult patient

\section{Abstract}

Pentalogy of Fallot (POF) is a variant of the more common Tetralogy of Fallot. We report the case of a 32-year-old man with asymptomatic POF, who was admitted to the department of acute medicine due to fracture of the lumbar vertebrae, and lumbar fusion was performed timely. No report of an adult with asymptomatic POF exists in the current literature. After 1.5 years, the patient returned to the hospital in order to remove the lumbar internal fixation.

(C) 2019 The Author(s)

Published by S. Karger AG, Basel 


\section{Introduction}

Pentalogy of Fallot (POF) is a variant of the more common Tetralogy of Fallot (TOF), including pulmonary stenosis (PS), a ventricular septal defect, right ventricular hypertrophy, and an overriding aorta with the addition of an atrial septal defect (ASD), and there is no epidemiological report. Asymptomatic POF is rare in adult congenital heart disease, especially in the emergency patient.

\section{Case Presentation}

An injured 32-year-old male Lanzhou Noodles Chef, who complained of lumbar pain as a result of falling injures, was admitted to the department of acute medicine on May 19, 2017. Fracture of the lumbar vertebrae was taken into consideration first, and the diagnosis was confirmed by magnetic resonance imaging examination (Fig. 1a). A resident doctor found a third intercostal II-IV/6 systolic murmur through auscultation of the heart. However, neither clubbing, cyanosis, palpitation, nor limitations of physical activity occurred in this patient. Blood pressure was $126 / 79 \mathrm{~mm} \mathrm{Hg}$, and heart rate was 74 beats/min. The oxygen saturation $\left(\mathrm{SpO}_{2}\right)$ of the patient was $96 \%$ (without oxygen inhalation).

Then, a detailed Doppler echocardiography was performed timely, and POF was diagnosed (Fig. 1b-d; Table 1). The examination with Doppler echocardiography also showed a normal heart function and slight dilatation of the right heart. With the cooperation of specialized cardiac surgical anesthesiologists, lumbar fusion was performed successfully in time. Postoperatively, the patient was admitted to the intensive care unit, and a ventilator was used to assist breathing. He returned to the general ward 2 days later and was discharged 8 days after surgery. During the hospitalization, the cardiac surgeon was consulted and recommended surgical treatment, but the patient refused.

One and a half years later, the patient returned to the hospital again in order to remove the internal fixation on November 16, 2018. We reviewed Doppler echocardiography, which indicated severe PS (Fig. 2a-c; Table 1) in comparison with moderate PS last time, and chest $\mathrm{X}$-ray, which showed no significant abnormality (Fig. 2d). In addition, the examination also found slight enlargement of the whole heart. In contrast, neither clubbing, cyanosis, nor limitations of physical activity occurred in this patient. The patient underwent general anesthesia to remove the lumbar internal fixation on November 19,2018 . His condition was stable postoperatively, and he was discharged 2 days later.

\section{Discussion/Conclusion}

There are several case reports of adult POF; these patients had symptoms of heart failure since childhood [1-4]. There is no global epidemiological report on POF. According to the literature on TOF, the incidence of TOF in congenital heart disease is $11-13.5 \%$, and about $10 \%$ of TOF patients have ASD [5]. Uncorrected TOF has a mortality of $75 \%$ by the age of 10 years and of $97 \%$ by the age of 40 years [6]. 


\section{Case Reports in Acute Medicine}

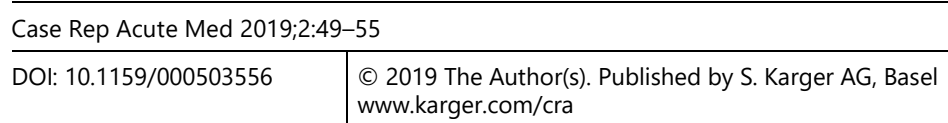

Lu et al.: Pentalogy of Fallot Firstly Diagnosed before Emergency Vertebral Surgery in an Adult Patient

Noncardiac surgery in asymptomatic patients with POF is rarely reported. There have been some cases of uncorrected POF in women undergoing caesarean section. Anesthesia is a great challenge for uncorrected POF patients. Maintaining systemic vascular resistance, avoiding elevations in pulmonary vascular resistance, maintaining preload, maintaining myocardial contractility, and avoiding reversal of shunt are the major anesthetic considerations for patients with POF [1]. It is crucial to avoid hypoxemia, hypercarbia, acidosis, and pain, all of which may increase pulmonary vascular resistance and contribute to reversal of shunt. Therefore, lowering blood pressure blindly for these patients might induce hypoxia.

There are no specific suggestions for unrepaired adult TOP/POF in the 2018 AHA/ACC Guideline for the Management of Adults with Congenital Heart Disease. There were subtle changes in the size of ASD and of the ventricular septal defect in the 2 examinations with Doppler echocardiography. We believe that the changes did not have a clinical significance, but the progression of PS was relatively obvious. We thought that PS was the most crucial lesion in POF, as has been reported [7]. However, the patient had no symptoms with aggravating stenosis of the pulmonary artery. Thus, the lumbar internal fixation was taken out successfully.

Living in the highlands (our city is at more than 1,500 m above sea level) was hypothesized to be conducive to enhancing this patient's tolerance of lung ischemia. We believed that this patient needed timely surgery during the compensation period. Otherwise, as the disease progresses, the patient would have cyanosis, and the prognosis might be worse. In addition, people with uncorrected POF/TOP might have a higher risk of brain abscess, cerebrovascular accident, and infective endocarditis [4, 8, 9]. Nevertheless, more clinical experience is necessary for determining the optimal time to operate according to the progression of PS.

Finally, the patient refused cardiac surgery again. We suggested that Doppler echocardiography should be conducted every 6 months during the follow-up of this patient.

\section{Acknowledgement}

None.

\section{Statement of Ethics}

The authors have no ethical conflicts to disclose. Informed consent was obtained from the patient for publication of this case report.

\section{Disclosure Statement}

The authors have no conflicts of interest to declare. 
Lu et al.: Pentalogy of Fallot Firstly Diagnosed before Emergency Vertebral Surgery in an Adult Patient

\section{Funding Sources}

The authors did not receive any financial support.

\section{Author Contributions}

X.L. and Y.Z. drafted the manuscript; W.D. provided echocardiography figures and legends. Y.T. performed 2 general anesthesia surgeries. D.L. contributed to the acquisition of the clinical data and provided a detailed review of the contents and structure of the manuscript. All authors have read and approved the final manuscript.

\section{References}

1 Ho YC, Boey SK, Varughese Mathews AM, See HG, Hwang NC. An Unusual Case of a Parturient with Uncorrected Pentalogy of Fallot Presenting for Elective Cesarean Section Delivery of Twins. Anesth Essays Res. 2018 Jan-Mar;12(1):267-70.

2 Tuluce K, Gurgun C, Yavuzgil O, Ceylan N, Tuluce SY. Two different pentalogies in an adult patient: a pentalogy of Cantrell associated with a pentalogy of Fallot. Eur Heart J Cardiovasc Imaging. 2012 Oct;13(10):878-9.

3 Aschwanden E, Bodenmann P, Schlueter L, Fivat-Arbane M, Hurni M, Qanadli SD, et al. Precordial abscess inducing chest pain 20 years after surgical repair of a pentalogy of fallot. Echocardiography. 2004 Aug;21(6):555-8.

4 Basheer M, Agarwalla SK. A rare association of pentalogy of fallot with situs inversus totalis complicated by brain abscess in an adolescent - case report. J Clin Diagn Res. 2016 Dec;10(12):SD06-07.

5 Zhou A. Cardiac Catheterization - Diagnosis and Treatment of Congenital Heart Disease. Jinan: Shandong Science and Technology Press; 1997. pp. 180-271.

6 Bertranou EG, Blackstone EH, Hazelrig JB, Turner ME Jr, Kirklin JW. Life expectancy without surgery in tetralogy of Fallot. Am J Cardiol. 1978 Sep;42(3):458-66.

7 Rabinovitch M, Herrera-deLeon V, Castaneda AR, Reid L. Growth and development of the pulmonary vascular bed in patients with tetralogy of Fallot with or without pulmonary atresia. Circulation. 1981 Dec;64(6):1234-49.

8 Ali H, Sarfraz S, Sanan M. Tetralogy of Fallot: Stroke in a Young Patient. Cureus. 2018 May;10(5):e2714.

9 Østergaard L, Valeur N, Ihlemann N, Bundgaard H, Gislason G, Torp-Pedersen C, et al. Incidence of infective endocarditis among patients considered at high risk. Eur Heart J. 2018 Feb;39(7):623-9. 


\section{Case Reports in Acute Medicine}

\section{Case Rep Acute Med 2019;2:49-55}

DOI: $10.1159 / 000503556$

(c) 2019 The Author(s). Published by S. Karger AG, Basel www.karger.com/cra

Lu et al.: Pentalogy of Fallot Firstly Diagnosed before Emergency Vertebral Surgery in an Adult Patient
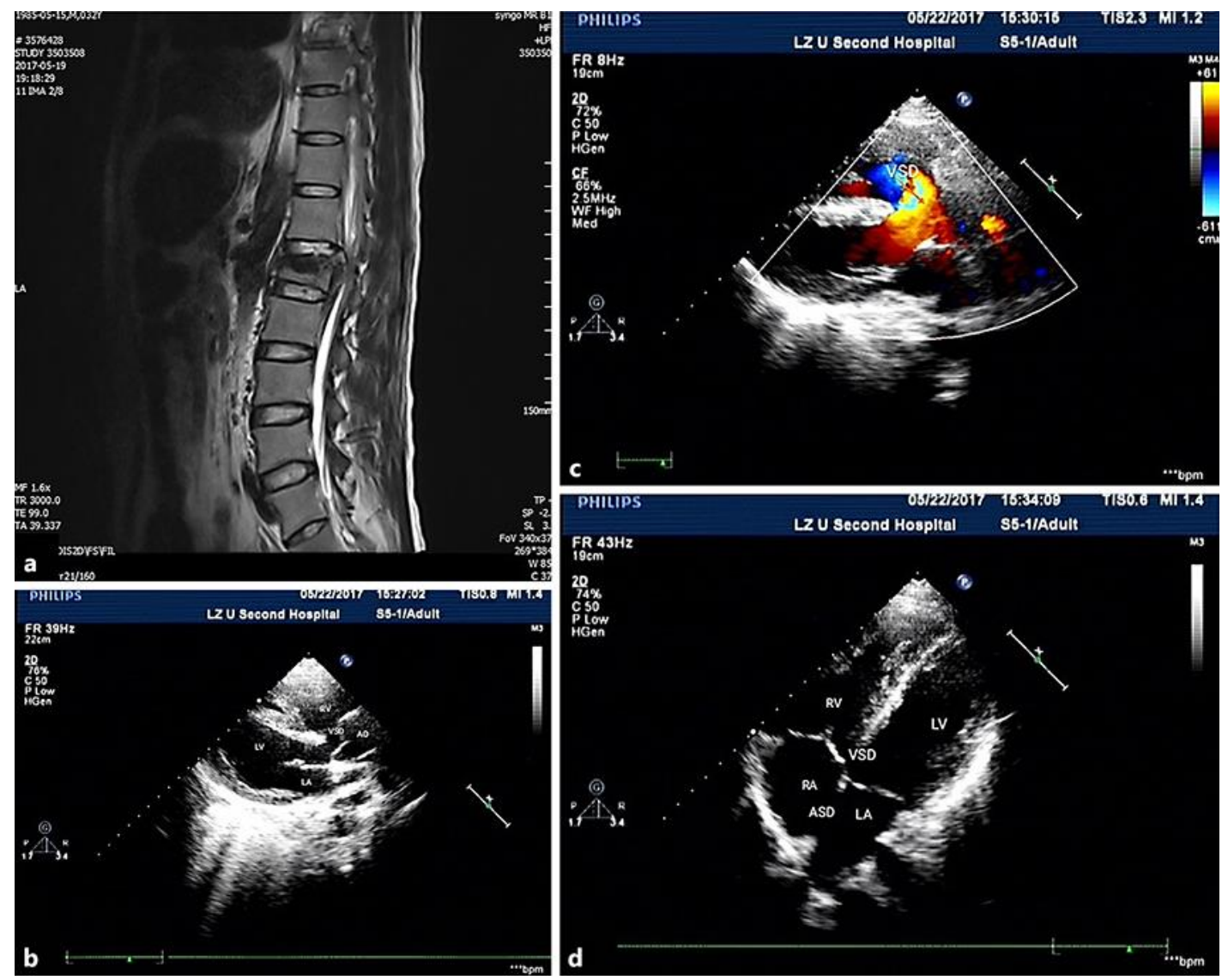

Fig. 1. a Magnetic resonance imaging examination of the lumbar spine. $\mathbf{b}$, $\mathbf{c}$ Right-ventricle long-axis view of Doppler echocardiography. d Four-chamber view of Doppler echocardiography. 


\section{Case Reports in Acute Medicine}

Case Rep Acute Med 2019;2:49-55

DOI: $10.1159 / 000503556$

(c) 2019 The Author(s). Published by S. Karger AG, Basel
www.karger.com/cra

Lu et al.: Pentalogy of Fallot Firstly Diagnosed before Emergency Vertebral Surgery in an Adult Patient
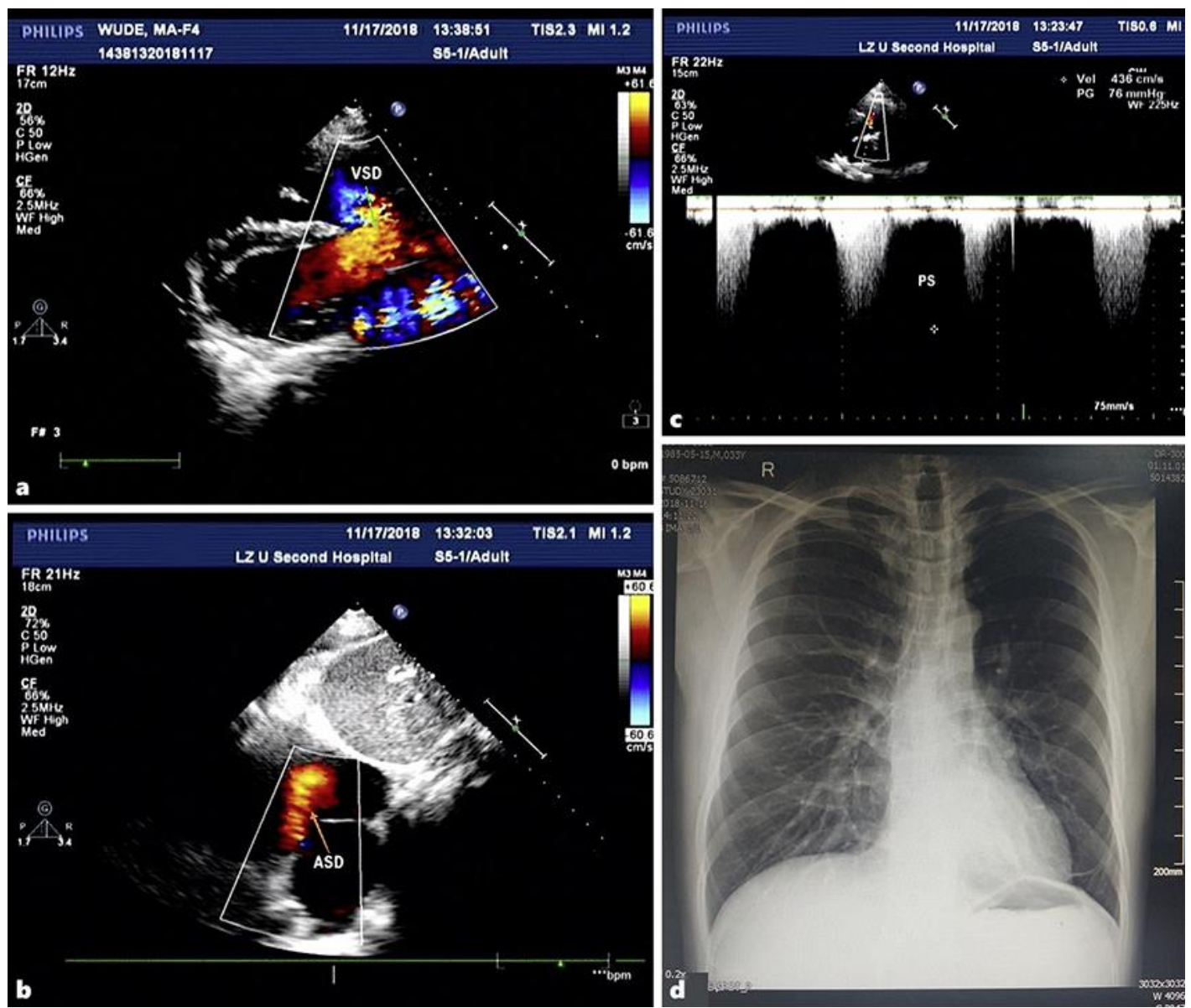

Fig. 2. a Right-ventricle long-axis view. b Two-cavity section of the atrium under the xiphoid process. c Peak flow velocity at pulmonary valve and transvalvular pressure gradient. $\mathbf{d}$ Normal chest X-ray (posterior anterior view). 


\section{Case Reports in Acute Medicine}

\begin{tabular}{l|l}
\hline Case Rep Acute Med 2019;2:49-55 \\
\hline DOI: 10.1159/000503556 & $\begin{array}{l}\text { @ } 2019 \text { The Author(s). Published by S. Karger AG, Basel } \\
\text { www.karger.com/cra }\end{array}$ \\
\hline
\end{tabular}

Lu et al.: Pentalogy of Fallot Firstly Diagnosed before Emergency Vertebral Surgery in an Adult Patient

Table 1. Detail information of Doppler echocardiography

\begin{tabular}{|c|c|c|c|c|c|c|c|c|c|}
\hline Year & $\begin{array}{l}\text { ASD, } \\
\mathrm{mm}\end{array}$ & $\begin{array}{l}\text { VSD, } \\
\mathrm{mm}\end{array}$ & Shunt direction & $\mathrm{PA}, \mathrm{mm}$ & $\begin{array}{l}\text { FVPV, } \\
\mathrm{cm} \times \mathrm{s}^{-1}\end{array}$ & PSG & $\begin{array}{l}\text { TPPG, } \\
\text { mm Hg }\end{array}$ & $\begin{array}{l}\text { LVEF, } \\
\%\end{array}$ & $\begin{array}{l}\text { Qp/ } \\
\text { Qs }\end{array}$ \\
\hline 2017 & 4 & 27 & $\begin{array}{l}\text { VSD: 2-sided } \\
\text { ASD: left-to-right }\end{array}$ & $\begin{array}{l}\text { Main: } 22 \\
\text { Left: } 14 \\
\text { Right: } 16\end{array}$ & 400 & M & 64 & 63 & 3.327 \\
\hline 2018 & 4.8 & 26 & $\begin{array}{l}\text { VSD: 2-sided } \\
\text { ASD: left-to-right }\end{array}$ & $\begin{array}{l}\text { Main: } 16 \\
\text { Left: } 11 \\
\text { Right: } 10\end{array}$ & 438 & S & 77 & 66 & 0.995 \\
\hline
\end{tabular}

ASD, atrial septal defect; FVPV, flow velocity at pulmonary valve; LVEF, left ventricular ejection fraction; M, moderate; PA, pulmonary artery; PSG, pulmonary stenosis gradient; S, severe; TPPG, transpulmonary pressure gradient; VSD, ventricular septal defect; Qp/Qs, pulmonary flow/systemic flow. 